\title{
EL ASUNTO DE CONCIENCIA EN KIERKEGAARD ${ }^{1}$
}

\author{
Matías Tapia Wende \\ Universidad de Los Andes, Chile
}

\section{Resumen}

Este artículo intenta mostrar cómo, a través de la reconstrucción histórico-filosófica del concepto de "asunto de conciencia" en Søren Kierkegaard, se pueden vincular la esfera existencial y la esfera política de su pensamiento, específicamente en la etapa que va desde 1847 hasta 1851. En las primeras dos secciones, se rastrea el asunto de conciencia y sus variantes en su obra publicada y sus Papirer, resaltando las determinaciones que apuntan tanto a la confirmación interna como al desenvolvimiento externo de la subjetividad. Con esta revisión a cuestas, se destacan en la tercera sección ciertos puntos de tensión -individuo, multitud y defensa del orden establecido- en torno a los que Kierkegaard está reflexionando en medio de la crisis política de Europa en general y de Dinamarca en particular. Finalmente, se concluye con la marcada impronta concreta y en potencia política que envuelve la filosofía existencial kierkegaardiana.

Palabras clave: Asunto de conciencia, existencia, individuo, cristianismo, política.

\section{Abstract}

In this paper, I attempt to show how, through a historical and philosophical reconstruction of the idea of "matter of conscience" developed by Søren Kierkegaard, it is possible to connect the existential and the political spheres of his thought, specifically during the period from 1847 through 1851. In the first two sections, I trace the matter of conscience and its variants within both his published works and his Papers, highlighting the determinations that point out towards the internal confirmation and the external unfolding of subjectivity. After this overhaul, I bring up in the third section three points of tension -the individual, the crowd, and the defense of the established order- about which Kierkegaard is thinking amid the European political crisis in general and the Danish one in particular. Lastly, I conclude maintaining the concrete and in potentia political power that is implicated in the Kierkegaardian

${ }^{1}$ Recibido el 5 de junio de 2020; aceptado el 22 de junio de 2020.

Este artículo fue escrito gracias al apoyo de ANID-Chile Proyecto FONDECYT Postdoctorado N. ${ }^{\circ}$ 3200167, con el patrocinio de Manfred Svensson. 
existential philosophy.

Keywords: Matter of conscience, existence, individual, Christianity, politics.

\section{Introducción}

El 20 de marzo de 1848, un grupo de liberales de segunda generación le entregó a Federico VII la moción por una Constitución libre para Dinamarca, incluyendo a Schleswig y promoviendo una ley electoral popular. Al día siguiente, más de quince mil personas marcharon hacia el palacio real y fueron recibidas por el rey, quien poco después anunció que había cesado en sus funciones a sus ministros. Ya para el 24 de marzo tenía un nuevo gabinete con paridad de liberales y conservadores, cuestión que dejaba allanado el camino para que la pacífica revolución danesa cumpliera su objetivo: pasar de una monarquía absoluta a una constitucional. El 5 de junio de 1849 la firma real sancionaba como vigente una nueva Carta fundamental en el país del norte.

Parte de lo que Søren Kierkegaard diagnostica sobre el contexto político inmediatamente anterior y posterior al movimiento revolucionario, se deja ver en las cartas que compartió con el prestigioso jurista J.L.A. KolderupRosenvinge. En una carta de julio o agosto de 1848, Kierkegaard le comenta a Kolderup-Rosenvinge que "la política no es para mí. Seguir la política, incluso tan sólo la política doméstica, es hoy en día una imposibilidad para mí, en todo grado" ${ }^{2}$ y no sin un dejo de ironía agrega un poco más abajo que "la política es demasiado para mí. Adoro enfocar mi atención en cosas menores" . Estas "cosas menores" indican hacia el que ha sido comprendido como el foco primigenio del pensamiento de Kierkegaard, esto es, la subjetividad. En otra de las cartas a Kolderup-Rosenvinge, fechada antes del 20 de agosto de 1848, Kierkegaard apunta que la condición europea de lo político es un vórtex (Hvirvel) y como tal busca un punto fijo en el que pueda parar: "Por lo tanto, verás, yo busco - dicho in parenthesi - a 'ese individuo singular" ". En una época en la que todo tiende hacia lo numérico, hacia las mayorías que se quieren hacer con el poder a través del voto, hacia la reformación del vínculo entre la Iglesia y el Estado, Kierkegaard destaca

${ }^{2} L D, 253$ / SKS 28, 391 .

${ }^{3}$ Ibíd.

${ }^{4} L D, 260-261 /$ SKS 28, p. 398. 
abiertamente que su atención está en lo que le ocurre al sujeto. Así las cosas, cabe la pregunta acerca de si se puede encontrar en Kierkegaard alguna contribución para pensar o mesurar lo político.

El objetivo de este artículo es mostrar precisamente que, a través del concepto de "asunto de conciencia", se puede conectar en el periodo revolucionario danés la esfera existencial-religiosa con la esfera política en el pensamiento de Kierkegaard. Por un lado, mi propuesta se asienta en que el asunto de conciencia es una categoría que es posible rastrear desde una perspectiva histórica y filosófica, acotándola justamente a la época en que Dinamarca está avanzando hacia un liberalismo moderado. Y, por otro lado, propongo que desde este posicionamiento surge positivamente una imagen de la individualidad cristiana que Kierkegaard quiere levantar en el escenario de crisis, al mismo tiempo que emergen de modo negativo los límites y las funciones que debería desempeñar la institucionalidad política en general y el Estado en particular. La conciencia sería en último término un puente entre la confirmación interior y el desenvolvimiento exterior de la singularidad o, lo que es lo mismo, entre el individuo religioso y el individuo ciudadano.

Entre 1847 y 1851, Kierkegaard recurrió a tres variantes para hablar del apego resuelto y activo que el sujeto despliega en torno a una idea: "asunto de conciencia" (Samvittighedssag), "cuestión de conciencia" (Samvittighedsspørgsmaal) y "constricción de conciencia" (Samvittighedstvang) $)^{5}$. Esta noción, con una clara referencia al ámbito práctico de una percepción tradicionalmente entendida como moral y kierkegaardianamente traducida en específico como cristiana, representa un lugar excepcional en el que se puede apreciar un correlato entre el contexto sociopolítico y el despliegue subjetivo que estaba llevando a cabo Kierkegaard.

En esta línea, en la primera parte de lo que sigue me encargaré de delimitar la manera en la que Kierkegaard introduce y articula el asunto de conciencia en su obra publicada, notando que los tres lugares en lo que esto ocurre - Las obras del amor, Discursos cristianos y "En ocasión de un comentario del Dr. Rudelbach sobre mí" - fueron firmados por el mismo Kierkegaard y escritos en circunstancias cruzadas por polémicas parecidas. Luego, en un segundo acápite, me abocaré a hacer el mismo recorrido, pero esta vez entre los Papirer. Espero notar a esta altura la conexión que hay entre lo que Kierkegaard está poniendo a disposición públicamente

${ }^{5}$ En este artículo, utilizaré las tres versiones como intercambiables, aunque respetando por supuestos las diversas traducciones en las citas. 
y lo que está comentando en el terreno más privado. Enseguida, en una tercera porción, voy a referir tanto a los aspectos existenciales y religiosos del asunto de conciencia, como a las cualidades políticas que se presentan desde ahí como contraste. El ánimo es que este análisis lleve hacia algunas consideraciones finales sobre un rol crítico que se le puede atribuir a la filosofía existencial de Kierkegaard y que se puede trasladar a nuestras propias crisis contemporáneas.

\section{El asunto de conciencia en la obra publicada}

En un borrador delaingente cantidad de artículos queestaba preparando en medio de su ataque final a la Iglesia estatal danesa, Kierkegaard escribe: "No tengo intenciones de tomar en cuenta objeciones anónimas, por la muy simple razón de que en un asunto de conciencia (Samvittighedenssag) es un sinsentido el anonimato" ". Si bien hay para Kierkegaard un abismo entre el poder comunicativo de la carencia de nombre y el de la autoría pseudónima, es notable que todas las referencias serias que hizo al asunto de conciencia estén dentro de obras homónimas. Es más, aparte de una breve mención en el título de una pieza de $1854^{7}$, el asunto de conciencia se deja ver en su enunciación directa sólo en tres publicaciones: Las obras del amor, Discursos cristianos y "En ocasión de un comentario del Dr. Rudelbach sobre mí". Esta tríada se ubica entre los años 1847 y 1851, justo en las puertas de la revolución, con la revolución encima y finalmente en medio de las discusiones sobre reformas al rol del Estado respecto de la Iglesia en el nuevo escenario constitucional. A continuación, voy a revisar de manera sucinta el asunto de conciencia en estas tres fuentes, marcando cuando sea posible tanto el aspecto interior-religioso como el exterior-político.

El escrito Las obras del amor comprende una serie de meditaciones cristianas separadas en dos partes, publicadas el 29 de septiembre de 1847. En una de las variantes del tercer apartado de la primera parte, Kierkegaard discurre acerca del amor en el cristianismo en tanto que un asunto de conciencia (Samvittighedens Sag), inspirado por un pasaje de la primera carta de Pablo a Timoteo: "Pero la suma de este mandato es la caridad que procede de un corazón limpio, de una conciencia recta

${ }^{6}$ TM, 450 / Pap. XI 3 B 33.

7 "¿Es esto adoración cristiana o es tener a Dios por tonto? (Una constricción de conciencia [Samvittighedsspørgsmaal] [para aliviar mi conciencia])", 21 de marzo de 1854. 


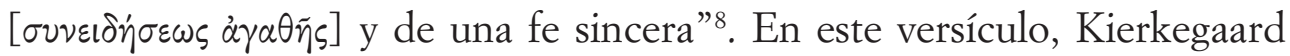
ve que el apóstol pone, contenida dentro de la conciencia, la atención a la observancia de la ley y el requisito para su pleno cumplimiento, esto es, en la base del amor que el cristianismo enfoca en el prójimo, está un movimiento de determinación interior que va a ser delineado por Kierkegaard como "el cambio de la infinitud en lo interno" ${ }^{9}$. Esta transformación está únicamente enfocada en modular "cada relación humana entre ser humano y ser humano en una relación de conciencia [Samvittighedens-Forhold]" ${ }^{10}$, y le es indiferente cualquier modificación externa. Refiriéndose en efecto a esta despreocupación de lo cristiano por lo relativo, Kierkegaard trae a colación en particular el aspecto político:

La pretensión del cristianismo no ha sido la de destronar gobiernos para entronizarse él; no ha disputado nunca, en un sentido externo, su sitio en este mundo, al que él no pertenece (pues si encuentra sitio en el recinto del corazón, no ocupa empero sitio alguno en el mundo); y sin embargo, ha cambiado infinitamente todo aquello que dejó y deja subsistir ${ }^{11}$.

Con un apunte algo más indirecto a lo institucional, Kierkegaard nota al matrimonio como una muestra clarificadora del vínculo que se establece a través de la conciencia, al mismo tiempo que refuerza la direccionalidad del interés cristiano. La interpelación del pastor a los contrayentes está enfocada en la consulta que ha hecho cada uno sobre su decisión con Dios y con su conciencia, y una vez confirmada esa fuerza resolutiva, se concreta la unión. Hay, por tanto, en este acto existencial-declarativo una conversión de la pasión amorosa, de la inclinación de un amante a otro, en una relación de conciencia. Sin embargo, Kierkegaard nota que sería un error pensar que este nuevo registro que alcanza lo pasional ha sido en específico el objetivo de la alteración de lo religioso. Lo que ocurre más bien es que, al haber hecho del amor en general un asunto de conciencia, el impulso de los que contraen matrimonio se transforma para el cristianismo también en un asunto de conciencia. Se entiende entonces que el cristianismo conserva la pasión amorosa, pero en el cambio de la infinitud en lo interno se produce el paso hacia una cuestión de resolución silenciosa e individual.

${ }^{8} \operatorname{Tim} 1: 5$.

9 Søren Kierkegaard, Las obras del amor, trad. de Demetrio Gutiérrez, Salamanca: Sígueme, 2006, p. 174 / SKS 9, 141.

${ }^{10}$ Ibíd., p. 169 / SKS 9, 137.

11 Ibíd. 
En este contexto, Kierkegaard sostiene que al cristianismo no le es relevante borrar las diferencias cuantitativas entre el hombre y la mujer: se mantiene el dominio del uno sobre la otra. Lo que importa es que cualitativamente, en el interior, no es más el hombre que la mujer, pues ambos están unidos en una relación de conciencia. Kierkegaard enfatiza, eso sí, que no es que el asunto de conciencia comience con el amor resignificado, sino que el amor se resignifica porque el cristianismo modifica la existencia entera del individuo. No hay algo así como un asunto de conciencia particular, reducido y pasajero, en tanto que el cambio de la interioridad involucra un nuevo registro a través del que todo se encarna en la existencia. Retrotrayendo la consideración, el amor conyugal tiene una forma primigenia en el amor al prójimo: "La esposa debe ser ante todo para ti el prójimo; que sea tu esposa constituye entonces una determinación más detallada" ${ }^{12}$. En todo momento debe conservarse un término medio, ya sea a Dios como el nexo hacia el prójimo, ya sea el prójimo como el nexo hacia Dios $^{13}$.

Aunque el amor sea una arista en la base amplia de la constricción de conciencia que el cristianismo siembra en la interioridad del sujeto, para ser tal no puede sino contener en sí las determinaciones que construyen este compromiso. De este modo, las cualidades del amor en tanto asunto de conciencia se pueden prolongar hacia lo que el asunto de conciencia envuelve en su noción existencial total. Justificado el parangón, el asunto de conciencia no es ni instinto ni inclinación, tampoco cuestión del sentimiento ni del cálculo racional. El asunto de conciencia es producto de un corazón limpio y de una fe sincera, es decir, surge de la elección interior del individuo ante Dios. Trasladando esto a un lenguaje existencial al que volveré más tarde, el asunto de conciencia emana de la puesta en tensión de lo humano concreto a través de lo que en la idealidad se muestra como labor divina. Si nos fijamos en el amor cristiano, se trata de la abolición formal y esencial de las diversas especies de amor para quedarse sólo con el amor al prójimo: un amor como determinación espiritual que se sustenta en la apropiación viva de la suma del mandato ${ }^{14}$.

Volvemos a encontrar el asunto de conciencia en otro compendio de mensajes religiosos, aparecido justo después de Las obras del amor. El 25 de abril de 1848, a casi un mes del cambio de gabinete de Federico VII, Kierkegaard publica Discursos cristianos, un texto separado en cuatro

${ }^{12}$ Ibíd., p. 175 / SKS 9, 143.

${ }^{13}$ Ibíd., p. 177 / SKS 9, 144.

${ }^{14}$ Cfr. Ibíd., pp. 178ss. / SKS 9, 145ss. 
partes. En la última sección de la tercera parte, Kierkegaard retoma sintomáticamente la primera carta de Pablo a Timoteo, seleccionando esta vez el versículo 16 del capítulo 3: "E indiscutiblemente, grande es el misterio de la piedad: Dios fue manifestado en carne, justificado en el Espíritu, visto de los ángeles, predicado a los gentiles, creído en el mundo, recibido arriba en gloria”. Dejando de lado la encarnación, la potencia espiritual, la agencia angelical, la labor evangelizadora y la reglorificación, Kierkegaard se asienta en que Dios haya sido creído en el mundo ( $\dot{\varepsilon} \pi\llcorner\sigma \varepsilon \dot{v} \theta \eta \dot{\varepsilon} \nu$ кó $\sigma \mu \omega)$, enfatizando que es en este foco prosaico que se cuela una apelación al fundamento de la resolución del individuo: "Pero en medio de lo histórico, usó [Pablo] unas pocas palabras que están dirigidas a ti. 'Fue creído en el mundo'; esto es, ¿has creído en Él?" ${ }^{15}$.

Apegado a su convicción de que lo existencial debe ser comunicado de manera indirecta, Kierkegaard afirma que, si se quiere presentar a alguien una cuestión de conciencia, ha de ser a través precisamente de la táctica del apóstol. Esta estrategia supone evitar que la demanda "se vuelva algo para lo que la respuesta sea sí o no (porque entonces la relación de conciencia se habrá intervenido)" 16 . En una modulación así, no se podría dar la confirmación interior y ante Dios de que la contestación es real. Por el contrario, lo que es necesario aplicar es la comunicación indirecta. El apóstol no llega y pregunta a Fulano y a Mengano si tienen fe en Dios. Lo que hace más bien es contar una historia, es alejar al oyente de la atención en sí mismo. Con este rodeo, la persona queda inseminada con la cuestión de conciencia, que emerge en plenitud luego cuando se ejercita la reflexión interna del mensaje: "[...] ahora dependes de ti mismo, de tu conciencia, para contestarte a ti mismo" 17 .

La seriedad radica en la soledad, en la tensión que brota allí donde las palabras y lo externo desaparecen como mera ocasión del asunto de conciencia. El horroroso poder que se manifiesta en este registro es distinto de cualquier otro. Cuando alguien nos hace una pregunta, dice Kierkegaard, "puedes arreglártelas para para engañarlo si es que no tienes ganas de contestarle o puedes enojarte y preguntarle con indignación quién se cree que es para venir a hacer esa pregunta, qué derecho tiene; pero aquí - ¡aquí no hay nadie!”18. A diferencia de la astucia retórica de

\footnotetext{
${ }^{15}$ CD, 235 / SKS 10, 242.

16 Ibíd.

${ }^{17}$ Ibíd.

${ }^{18}$ CD, 236 / SKS 10, 243.
} 
Ulises frente a Polifemo, el individuo que ha alcanzado un cierto grado de conciencia no puede escapar ni de sí mismo ni de Dios, y debe enfrentarse solemnemente a la encrucijada. Kierkegaard llega con esto a separar en dos esferas cualitativamente distintas el mensaje de Pablo. Por un lado, está el aspecto histórico y concreto de que Dios haya sido creído en el mundo y, por otro, está la confirmación interior de cada sujeto de que Dios ha sido en efecto creído en el mundo. Sólo cuando uno mismo llega a responder afirmativamente la cuestión de conciencia, sólo entonces uno puede tener la certeza de que hay fe en la Tierra: "Una persona no puede meterse en el corazón de otra, donde vive la fe o, más bien, donde se ve si la fe está presente o no - esto es, sólo el individuo singular sabe en sí mismo y ante Dios si cree o no" ${ }^{19}$.

Las consecuencias de la forma en la que Kierkegaard expone la cuestión de conciencia en Discursos cristianos se muestran por supuesto y en primera instancia en aquella presión interior, pero también desbordan hacia la esfera de lo externo e incluso de lo político. En tanto que el asunto de conciencia, ligado indefectiblemente a lo religioso, supone una confirmación encerrada en la subjetividad y una subsecuente traducción existencial, Kierkegaard rechaza el esquema de la cristiandad oficial que intenta imponer un marco en el que todos los nacidos bajo el brazo del Estado danés son cristianos y son intensamente educados en las mil aristas de erudición que exige la doctrina. La cuestión de conciencia no se da en la cristiandad precisamente porque no ocurre en los sujetos una "transformación interior del espíritu todo, a través de la que una persona en peligro de perder su espíritu llega con seriedad, con verdadera interioridad, a creer al menos algo - de lo que conoce en gran cantidad sobre el cristianismo" ${ }^{20}$.

Esta conversión, no obstante, no entraña una directa oposición al orden establecido o a las instituciones políticas. Kierkegaard da la impresión de que la persona resuelta en conciencia tiene la "disposición" a dejarlo todo por su fe, es decir, tiene como una posibilidad siempre acechante aquella de tener que renunciar a sí misma y a todo lo externo si así lo demanda la divinidad, pero entretanto se puede seguir desempeñando como una ciudadana común y corriente. Bruce Kirmmse ha llamado "prioritarismo" a esta visión que Kierkegaard comenzó a construir en 1843 en Temor y temblor, y que vino a borrar del mapa en 1854 y 1855 con su ataque a la Iglesia estatal de Dinamarca. Kirmmse denota que el Kierkegaard prioritarista considera

${ }^{19}$ CD, 237 / SKS 10, 244.

${ }^{20}$ CD, 246 / SKS 10, 252. 
que "la preocupación respecto de los asuntos del mundo no está mal en sí misma, pero debe ser vista como subordinada a la relación del individuo con Dios" 21 .

Rasgos de este prioritarismo y todavía más determinaciones del asunto de conciencia, son expuestos por Kierkegaard en la última fuente que nos dejó con un desarrollo dedicado del concepto. Saliéndose del ámbito de las meditaciones y discursos cristianos, con "En ocasión de un comentario del Dr. Rudelbach sobre mí”, carta abierta impresa el 31 de enero de 1851 en el diario Fædrelandet, Kierkegaard traslada al terreno polémico y público sus indicaciones acerca de la subjetividad decidida. A.G. Rudelbach era un teólogo cercano a las ideas de N.F.S. Grundtvig y desde ahí opositor activo del racionalismo religioso reinante en la Época de Oro danesa, aunque precursor de una revitalización del vínculo con la Iglesia luterana ${ }^{22}$. En un ánimo precisamente grundtvigiano inclinado hacia un modelo de Iglesia libre, Rudelbach publicó Sobre el matrimonio civil en enero de 1851, obra en la que "argumentaba por la institución del matrimonio civil como parte de la campaña de separación de la Iglesia y el Estado en la que estaba comprometido el partido de Grundtvig" ${ }^{23}$. Buscando trazas de criticismo en la escena intelectual contemporánea, Rudelbach escribe:

[...] en verdad, es justamente el interés más alto y más profundo de la Iglesia en nuestros tiempos [...] emanciparse de lo que con razón puede llamarse el cristianismo de hábito y legalmente establecido [...]. Esto es lo mismo que uno de los más excelentes escritores de nuestro tiempo reciente, Søren Kierkegaard, busca enfatizar, representar y - como dice Lutero - impulsar en toda persona que quiera escuchar $[\ldots]^{24}$.

Kierkegaard defiende que este enrolamiento que le achaca Rudelbach en la actividad emancipadora del cristianismo establecido es sólo parcialmente verdadero y, por lo tanto, es también parcialmente falso. En este sentido, Kierkegaard en efecto se reconoce como "un enemigo del 'cristianismo de hábito'" 25 , pero acentúa que repulsa cualquier cara que tomela tergiversación cristiana en tanto que reforma exterior. Su posición es tan enfática que, junto con ofrecer una recompensa a quien encuentre entre sus escritos

${ }^{21}$ Bruce Kirmmse, Kierkegaard in the Golden Age Denmark, Bloomington e Indianápolis: Indiana University Press, 1990, p. 295.

${ }^{22}$ Cfr. COR, xxxvi-xxxvii.

${ }^{23}$ Kirmmse, Kierkegaard in the Golden Age Denmark, p. 419.

${ }^{24}$ COR, 51 / SKS 14, 111.

${ }^{25}$ COR, 52 / SKS 14, 111. 
algún atisbo de esperanza de cambio en el mundo, Kierkegaard añade sin conservar un particular tacto que "no he peleado por la emancipación de la Iglesia más de lo que he peleado por la emancipación de Groenlandia, del comercio, de las mujeres, de los judíos o de cualquiera" ${ }^{26}$. Contrastando con esta supuesta preocupación por lo relativo, Kierkegaard aclara que lo que ha cruzado como un hilo rojo su producción ha sido el trabajo diligente y honesto "por la profundización interior del cristianismo en mí mismo y en otros, en tanto ellos quieran ser influenciados" 27 , y la lucha contra cualquier desastrosa confusión entre la política y el cristianismo que lleve a creer que en lo externo, que en la diversidad cuantitativa, que en la democracia está lo decisivo.

Comparando a la política con Tántalo, el desgraciado hijo de Zeus que fue condenado a nunca poder saciar ni su hambre ni su sed, Kierkegaard enmarca al cristianismo como una "indiferencia con lo externo, en preocupación de sí mismo" 28 . Con esto arribamos a otra representación prioritarista, pero hay un detalle que Kierkegaard agrega y que cambia de tono el panorama, sobre todo por el alcance que tendrá su proyección con el pasar de los años. Sin dejar de sostener que lo cristiano es esencialmente interioridad, Kierkegaard nota que hay un espacio para el enfrentamiento entre el creyente y lo externo: "Si en un momento dado, las formas bajo las cuales se debe vivir no son las más perfectas, si se pueden mejorar, hazlo en nombre de Dios" ${ }^{29}$. Esta colisión no implica para Kierkegaard otra cosa que un asunto de conciencia, una firme resolución del individuo ante Dios y la disposición a llegar al martirio con tal de actuar de acuerdo con su contenido ideal:

Si alguien choca con el orden establecido de manera que piense que es una cuestión de conciencia - ¡Dios, una cuestión de conciencia! - y se atreva a decirlo, debe entonces estar solo para recorrer el sufrimiento, para elegir el martirio. La conciencia y una cuestión de conciencia pueden ser representadas sólo a través de la acción de una persona solitaria y de carácter, por la acción, nunca en una discusión que va a concluir en un voto ${ }^{30}$.

\footnotetext{
${ }^{26}$ COR, 54 / SKS 14, 113.

27 COR, 53 / SKS 14, 112.

${ }^{28}$ COR, 57 / SKS 14, 115.

${ }^{29}$ COR, 53 / SKS 14, 112.

${ }^{30}$ COR, 57-58 / SKS 14, 115.
} 
Kierkegaard rechaza que la Iglesia y el Estado se puedan salvar o reformar por medio de instituciones libres, como el matrimonio civil que proponía Rudelbach. Si en algo le concierne a Kierkegaard la rectificación del Estado respecto de su rol con la Iglesia, es en cuanto supresión de las ilusiones que los movimientos políticos han provocado en la gente común. Kierkegaard se precia de haber proveído poéticamente al orden establecido con un correctivo-existencial (Existential-Correctiv), orientado al desarrollo de la interioridad individual y dirigido polémicamente "hacia 'la multitud', lo numérico, también hacia el pecado dominante de nuestro tiempo, reformaciones autoproclamadas y las falsificaciones consiguientes" ${ }^{31}$. Así, Kierkegaard le cede su lugar al Estado como parte de lo relativo en la externalidad, pero cuela al mismo tiempo la posibilidad de que un individuo trastoque en un asunto de conciencia su oposición con el orden establecido. Este tipo de enfrentamiento, asegura Kierkegaard, es el único que podría introducir una verdadera reforma, aunque proveniente y centrada en la interioridad.

El derrotero que sigue la cuestión de conciencia desde Las obras del amor, escrito a las puertas de la revolución, hasta la carta abierta a Rudelbach, situada en medio de discusiones eclesiásticas en el nuevo escenario político constitucional, anuncia tanto un reforzamiento de la idea kierkegaardiana sobre el individuo en tanto lugar de resistencia y crítica de lo externo, como la encarnación de este modelo que se va a arrogar Kierkegaard cuando su paciencia con el orden establecido se quiebre. Más adelante desarrollaré específicamente el primer punto, dejando entrever algunos visos del segundo.

\section{Asunto de conciencia en los Papirer}

En el cuaderno signado como NB22, inaugurado el 13 de noviembre de 1850 y terminado no después del 22 de enero de 1851 - es decir, nueve días antes de la publicación de la carta abierta a Rudelbach -, Kierkegaard apunta hacia los peligros que se agolpan para la verdad y para el verdadero cristiano cuando se presume que lo decisivo pasa por la voz de la mayoría: "Los cuáqueros hicieron un asunto de conciencia el que los cristianos no fueran a la guerra. Yo quisiera preguntar si votar sobre lo que constituye la

${ }^{31}$ COR, $56 /$ SKS 14, 114. 
verdad no es un asunto de conciencia para el verdadero cristiano" ${ }^{32}$. Luego de esta alusión al asunto de conciencia, sólo nos llegan siete más, todas dispuestas en el siguiente compendio de fragmentos.

De entre las 228 entradas del cuaderno NB23, utilizado por lo menos hasta el 20 de abril de 1851, únicamente una de ellas tiene fecha: sabemos que el pasaje 180 fue incluido el 9 de marzo. Esta mínima evidencia muestra que las menciones al asunto de conciencia fueron anotadas entre fines de enero y principios de marzo de 1851. La primera de ellas llama la atención sobre la seriedad que encierra la constricción de conciencia. Kierkegaard sostiene que es muy fácil y ciertamente solemne "invocar la conciencia y quejarse acerca de la opresión de conciencia [SamvittighedsTryk]"33. El problema es que un movimiento así está a un paso de caer en la autorevelación o, lo que es lo mismo, en la inauténtica exteriorización de la interioridad. Cuando la libertad ha alcanzado la fuerza suficiente como para querer arriesgarlo todo, dice Kierkegaard, el sujeto permanece en buenos términos con su conciencia y acepta el riesgo. Cualquier otro tipo de filtración de inseguridad es señal de que nunca se trató de un asunto de conciencia. Este diagnóstico existencial se vuelca hacia lo público en el fragmento siguiente. Kierkegaard condiciona que "los asuntos de conciencia no se pueden representar iniciando discusiones... porque la persona que inicia una discusión percibe de antemano que no va a ganar" ${ }^{34}$. Así, con aires a la lectura hegeliana del héroe trágico griego, Kierkegaard afirma que el individuo que lleve adelante un asunto de conciencia debe estar al tanto de que su ser completo está implicado en su empresa: "O debe ganar o va a sucumbir - de otra manera, no le está realmente permitido decir que tiene un asunto de conciencia" 35 .

Cinco espacios más abajo, Kierkegaard retoma el elemento existencial, comentando que es una tontería expresarse sobre un asunto de conciencia o declamar que es mucho lo que se está dispuesto a sacrificar. El único escenario contundente lo encarnaría aquel que contenga a una persona que "permanezca en silencio, pero que su vida exprese que ha arriesgado todo por lo religioso: eso sería un asunto de conciencia" ${ }^{36}$. Kierkegaard reconoce lo insidioso que es este registro, por lo que ofrece una cierta salida

${ }^{32}$ JP 4, 4874 / SKS 24, 131, NB22:49.

${ }^{33}$ JP 4, 4935 / SKS 24, 213, NB23:18. Samvittigheds-Tryk aparece sólo en esta entrada.

${ }^{34}$ JP 4, 4936 / SKS 24, 213, NB23:19.

${ }^{35}$ JP 4, 4936 / SKS 24, 213-214, NB23:19.

${ }^{36} \mathrm{JP}$ 1, 686 / SKS 24, 217, NB23:24. 
para aquellos cuyo espíritu no alcanza todavía la potencia necesaria: "Pero nosotros, tal como somos, somos mucho más débiles y frágiles como para tener asuntos de conciencia, para ser capaces de soportar tener asuntos de conciencia" ${ }^{37}$. La cristiandad, la ilusoria multitud de cristianos de hábito que ha creado el Estado, debería ser capaz de hacer un reconocimiento honesto y cuadrarse al menos en el abajamiento ante Dios.

Casi con un ritmo tácito, el equilibrio kierkegaardiano alterna de nuevo hacia lo externo un par de pasajes más adelante. Refiriéndose al cambio de cualidad que puede sufrir la dirección del cristianismo, Kierkegaard abre la posibilidad de que, si debe haber un asunto de conciencia encauzado hacia afuera, "debe ser porque el orden establecido es pura y simple impiedad" 38 . De no darse este requisito, la cualidad se transmuta y el cristianismo se mantiene como una indiferencia a cualquier preocupación o involucramiento esencial con lo externo. Aquí se introduce, eso sí, un detalle central. Kierkegaard especifica que, aunque la interioridad del cristiano deba resguardarse en un contexto en el que no haya confrontación que invoque un asunto de conciencia, no debe sin embargo ser pura interioridad oculta. En tensión con lo que señala junto a sus seudónimos hasta principios de 1846, Kierkegaard va resignificando el alcance de la subjetividad a medida que ve los cambios políticos en Dinamarca. De esta forma, la interioridad que presenta entre 1846 y 1851, entraña "el aspecto ético del cristianismo" 39 , esto es, una especie de alerta o de disposición esencial de lo religioso a las colisiones que puedan darse con lo circundante y que desencadenen eventualmente el martirio. El cristiano, si bien es indiferente en cuanto a asuntos políticos como la emancipación de la Iglesia o la reformulación del Estado, debe estar en cualquier caso dispuesto a enfrentarse a la institucionalidad cuando sea un asunto de conciencia. En su época, Kierkegaard ve estos detonantes en el dominio de la multitud y en la debilidad de los líderes políticos, que creen poder rescatar la religión a punta de enmiendas, discusiones y votaciones.

Avanzando ocho entradas, lo existencial toma ahora la forma de lo psicológico. Kierkegaard bosqueja los aspectos de la psiquis de quien está en medio de un asunto de conciencia: "La persona que tiene un asunto de conciencia no sólo no busca ayuda terrenal, no busca evitar problemas ni 'el camino más fácil', no, busca peligros, crea dificultades para sí misma,

37 Ibíd.

${ }^{38}$ JP 2, 2130 / SKS 24, 217, NB23:26.

${ }^{39}$ JP 2, 2130 / SKS 24, 218, NB23:26.

Estudios Kierkegaardianos. Revista de filosofía 6 (2020) 
descubre el camino más difícil" ${ }^{40}$. Allí donde no se dé este indicio, sentencia Kierkegaard, no hay en estricto rigor un asunto de conciencia. Tal como un funcionario de banco se fija en los más mínimos detalles para reconocer una nota de crédito falsa, tal como un corredor inspecciona un billete para ver errores de impresión hasta en la ínfima floritura, tal como el médico no inclina su diagnóstico hacia una enfermedad cuyo síntoma distintivo no está presente, del mismo modo se puede identificar un asunto de conciencia carente de autenticidad. No bien esto, otra precaución debe tomarse. El gesto es hacia reconocer la falsificación, no hacia confirmar la autenticidad: que estén los aspectos psicológicos no sanciona la presencia de un acto de conciencia. Pareciera que Kierkegaard con esto se cuida de algún tipo de expresión de decisión que no quepa dentro de la categoría del cristianismo, sino que se pase hacia el fanatismo.

Dos fragmentos más abajo, Kierkegaard vuelve sobre lo estataleclesiástico con la penúltima mención como tal al asunto de conciencia. Con un eco irónico en la intención de Grundtvig y sus seguidores de conseguir una Iglesia libre, Kierkegaard confiesa que no tiene nada en contra del hecho de que estos viejos ortodoxos se quieran separar del orden central. No obstante, lo que sí considera indefendible es que "lo hagan con votaciones y sin renunciar a su reivindicación de ser la verdadera Iglesia” ${ }^{41}$. Kierkegaard menciona específicamente a N.M. Spandet, un jurista y político cercano a las ideas de Grundtvig y desde 1849 representante de la izquierda en la cámara baja del neonato Parlamento danés. Hacia fines de 1850, Spandet había presentado un proyecto de ley para promover la libertad de religión, por medio de la introducción del matrimonio civil y de la abolición del bautismo y la confirmación como obligaciones civiles:

¿Cuál habrá sido el ánimo del noble Spandet cuando envío su propuesta? La veía como algo parecido a una sugerencia en torno al alumbrado público o cosas de esa naturaleza - bueno, en ese caso, ciertamente que se puede votar - pero hubiera sido por supuesto impropio que la hubiera enviado en ese ánimo. O si asegura ver esto como un asunto de conciencia, entonces cómo diantres podría estar satisfecho sirviendo a un asunto de conciencia - el que, dado que es en "servicio de Su Majestad", no debería ser tomado a la ligera y debería prevalecer, pero debe prevalecer o la persona a cargo debe sucumbir - al proponer algo para ser votado y luego ver cuántos votos consigue ${ }^{42}$.

${ }^{40} J P$ 1, 687/ SKS 24, 223, NB23:34.
${ }^{41} J P$ 6, 6728 / SKS 24, 224-225, NB23:36.
${ }^{42} J P$ 6, 6728 / SKS 24, 225, NB23:36. 
Kierkegaard saca las paradójicas cuentas de este emprendimiento político. Si el proyecto pasa y se transforma en ley, el apoyo de una mayoría va a ser prueba indirecta de que lo que estaba en juego no era un asunto de conciencia. Por otro lado, si su moción pierde, lejos de caer Spanget con ella, es posible que sea visto como un personaje con gran carácter y arrojo por sus convicciones. Sobra decir que Kierkegaard no ve aquí tampoco nada cercano a un asunto de conciencia.

Finalmente, acercándose a las dos centenas de fragmentos en la cuenta del NB23 y a propósito de un libro sobre los principios del socialismo del teólogo suizo A.R. Vinet, Kierkegaard abrocha sin rodeos la determinación existencial del sujeto y su posible externalización polémica con lo político. Hablando desde un punto de vista cristiano, Kierkegaard sienta la determinación de que "dejar que el individuo simplemente se subsuma al Estado es paganismo y el fin de toda verdad - que, en conciencia, el individuo está por encima del Estado" "3 . Con una espiritualización de lo que en Vinet es una inmediatez todavía adolescente, la singularidad kierkegaardiana entraña en su núcleo heroico la potencia de "chocar con un orden establecido por el bien de la conciencia" ${ }^{4}$, si es que se dan las condiciones hostiles. El problema es que, en medio de la complacencia de la demagogia, que presupone Kierkegaard, se borra hasta por ley la conciencia y desaparece también la presencia de un Estado firme que presione hacia la oposición. En la modernidad, la dispersión oscurece el panorama para la resolución ética y por tanto concreta, transfigurando todas las determinaciones como estertores de una abstracción que celebra la inanición espiritual. Es éste el escenario el que le sirve a Kierkegaard como el fundamento por el que "precisamente por el bien de la conciencia - exijo compulsión" 45.

A diferencia de lo que ocurre en la obra publicada, el asunto de conciencia se muestra en los Papirer exclusivamente asociado a la crítica que Kierkegaard construye en lo privado y en lo público hacia Rudelbach. Sin embargo, los rasgos que aparecen son los mismos: la determinación existencial positiva del individuo cristiano y el contrapunto negativo de la política como indiferente o como antagonista frente a la resolución religiosa. En la siguiente sección, voy a poner en diálogo estas diversas características,

${ }^{43}$ JP 2, 2037 / SKS 24, 292, NB23:181, 1851. Kierkegaard usa Samvittigheds-Collision en el título de esta entrada.

${ }^{44}$ JP 2, 2037 / SKS 24, 292, NB23:181, 1851.

${ }^{45}$ Ibíd. 
intentando profundizar en la subjetividad que Kierkegaard está levantando y el vínculo que puede tener con la articulación externa.

\section{Asunto de conciencia en la relación entre lo existencial y lo político}

El 22 de diciembre de 1845, poco después de que Kierkegaard entregara a la imprenta el manuscrito del Postscriptum, P.L. Møller, un intelectual liberal cercano a H.C. Andersen y a figuras ligadas a la prensa satírica, publicó el número anual de su revista Gæa. Esta nueva tirada venía coronada por un extenso artículo del mismo Møller, "Una visita a Sorø", en el que recuenta las conversaciones que tuvo con algunos críticos literarios sobre los libros daneses más connotados del último tiempo, entre los que estaban por supuesto los de Kierkegaard. Si bien hubo ciertos elogios para su concepción estética, Møller y sus secuaces no fueron del todo benévolos con la pasión productiva kierkegaardiana en general. Como era de esperarse, Kierkegaard no se quedó con los brazos cruzados y el 27 de diciembre mandó al Fædrelandet una feroz respuesta, firmada por el seudónimo Frater Taciturnus, con el insinuador título "La actividad de un esteta viajero y cómo aun así logra pagar la cena”. Con esta pieza se inició una de las más grandes polémicas que Kierkegaard tuvo en vida y "la más famosa controversia literaria en la historia danesa" ${ }^{46}$.

La batalla involucró a Kierkegaard con El corsario, un diario satírico supuestamente dirigido por el liberal A.M. Goldschmidt, pero en realidad controlado por Møller. Las arremetidas que fueron apareciendo en El corsario apuntaban a ridiculizar desde el aspecto físico de Kierkegaard hasta sus delirios de grandeza como escritor. Más allá de los valiosos elementos que se pueden leer en este conflicto, sobre todo en las anotaciones personales de Kierkegaard, lo que considero radicalmente importante es el quiebre que se percibe en su obra después de amainada la tormenta. Ejercitando una comprensión retrospectiva, Kierkegaard escribió en 1850: "Cuando publiqué el Postscriptum, mi intención era retirarme y concentrarme más en mi propia relación con el cristianismo. Pero en el entretanto las circunstancias externas de mi vida pública estaban dispuestas de tal manera que descubrí existencialmente las colisiones cristianas" ${ }^{47}$. Esta nueva etapa muestra a un Kierkegaard más enfático en desarrollar la importancia del individuo

${ }^{46} \mathrm{COR}$, xvii.

${ }^{47}$ JP 6, 6660 / SKS 23, 427, NB20:61. 
singular y de la religión, contrastando con los alcances de la multitud y de la política como determinaciones de una modernidad deformada. Lo que haré a continuación será dar cuenta de algunas aristas centrales de la subjetividad kierkegaardiana de 1846-1851, con un constante apunte hacia el asunto de conciencia y hacia los posibles encuentros con el terreno político.

En mi lectura, lo que se yergue como punto capital a partir de 1846 es la plena seguridad de Kierkegaard de que el sujeto es el medio de transformación que demandan las condiciones externas. En Una reseña literaria, publicada el 30 de marzo de 1846, Kierkegaard dispone que no es "ni remotamente probable que la idea de sociabilidad [...] sea lo que salve a la época" ${ }^{48}$. Por el contrario, es de hecho esta misma suspicacia la que se necesita como estímulo para el desarrollo auténtico, esto es, religioso de la individualidad y para la subsecuente remodulación del esquema externo. El diagnóstico de Kierkegaard es que "en nuestra época el principio de asociación [...] no es afirmativo, sino negativo; es una evasión, una disipación, una ilusión" ${ }^{49}$, cuya tensión dialéctica nivela el empoderamiento de los sujetos y debilita el principio ético del singular por medio del refuerzo numérico o masivo. Frente a esto, lo que debe ejecutarse es un proceso de concientización para que cada sujeto emprenda el desarrollo reflexivo y el descubrimiento de sus determinaciones potenciales: "No antes de que el individuo gane en sí mismo una postura ética a pesar de todo el mundo, no antes de ello podrá hablarse en verdad de unir; de otro modo la unión de los que por sí solos son débiles se vuelve algo tan feo y depravado como el matrimonio entre niños"

En su intercambio epistolar con Kolderup-Rosenvinge, Kierkegaard machaca esta noción de revitalización in dividual y la lleva un peldaño más allá en su eventual intervención política. En la carta de agosto de 1848 citada en la introducción, Kierkegaard le apunta a Kolderup-Rosenvinge como vimos que la condición europea de lo político es un vórtex y que en ese contexto lo que él busca es "ese individuo singular" ${ }^{51}$. Haciendo gala de sus dotes de analogista, Kierkegaard se vale enseguida de la noticia de un carpintero aplastado por un nuevo sistema de frenos implementado en algunos trenes de Europa, mientras juega con el doble significado de Bremse en danés, que

${ }^{48}$ Søren Kierkegaard, La época presente, trad. de Manfred Svensson, Madrid: Trotta, 2012, p. 85 / SKS 8, 100.

${ }^{49}$ Ibíd.

${ }^{50}$ Ibíd., p. 86 / SKS 8, 100-101.

${ }^{51}$ LD, 260-261 / SKS 28, 398. 
puede referir tanto a "freno" como a "tábano" o "moscardón" 52 . En esta línea, Kierkegaard le sostiene a Kolderup-Rosenvinge que "todo movimiento puramente político, que en consecuencia carece del elemento religioso o es renegado por Dios, es un vórtex, no puede ser detenido y es presa de la ilusión de querer un punto fijo adelante, lo que es querer detenerse por medio de un freno [Bremse]; pero el punto fijo, el único punto fijo, está detrás" ${ }^{53}$. Apoyado en este principio que entraña específicamente una crítica al infinito vaivén político en la restructuración de la institucionalidad danesa, Kierkegaard cree que toda la confusión que se ha esparcido en general por Europa sólo puede ser atajada en una vuelta a la religión: "El movimiento de nuestro tiempo, que parece ser puramente político, se va a transformar de pronto en religioso o en la necesidad de religión" ${ }^{54}$. Si se hiciera el amago de ocupar el registro político para detener el enfrentamiento, sería tan inútil como intentar frenar un tren con un tábano y Europa seguiría estando encarnada en el desafortunado carpintero.

En este ordenamiento de cosas, Kierkegaard asume que para hallar ese punto fijo que yace en la partida del movimiento, se requiere de la expresión decidida de la subjetividad cristiana. Echando mano de la figura socrática como el tábano que detuvo el vórtex de los sofistas, Kierkegaard se muestra convencido de que la conmoción moderna cederá ante la superioridad del mártir, que "conquista como el hombre muerto que retorna" 55 . Las implicancias políticas de esta exigencia religiosa quedan aún más a la vista cuando Kierkegaard le dice seriamente a Kolderup-Rosenvinge: “¿Cómo podría haber sabido que usted estaba esperando un tirano, mientras yo espero un mártir?" ${ }^{6}$. Es aquí, por tanto, que asistimos a un Kierkegaard que está haciendo un bosquejo privado que casi tres años después le va a exponer públicamente a Rudelbach en términos de un sujeto chocando con el orden establecido, a través de la expresión existencial de un asunto de conciencia.

A partir de 1846, las publicaciones de Kierkegaard se fueron haciendo más esporádicas, al menos si se hace la comparación con la profusa cantidad de títulos que vieron la luz a partir de 1843. Sin embargo, este silencio

${ }^{52}$ Cfr. LD, 479n. y Michael Tilley, "Herbert Marcuse: Social Critique, Haecker, and Kierkegaardian Individualism”, en Kierkegaard's Influence on Social-Political Thought, ed. de Jon Stewart, Farnham: Ashgate, 2009, p. 81.

${ }^{53}$ LD, 262 / SKS 28, 400.

54 Ibíd.

${ }^{55}$ LD, 262 / SKS 28, 400.

${ }^{56} \mathrm{LD}, 271$ / SKS 28, 409. 
creativo no se debió a falta de material, sino a constantes deliberaciones por parte de Kierkegaard en torno a la forma y al contenido del mensaje que quería esparcir. Preocupado por alcanzar una comprensión transversal de su metodología literaria, Kierkegaard comenzó a preparar algo así como folletos explicativos, entre los que se cuentan Mi punto de vista, Neutralidad armada y Sobre mi actividad como escritor. Este último sería el único borrador que Kierkegaard se decidió a entregar a imprenta, siendo publicado finalmente el 6 de agosto de 1851, siete meses después de la carta abierta a Rudelbach. Por otro lado, en paralelo a este ejercicio de metaescritura, Kierkegaard tenía entre manos la emergencia de un nuevo seudónimo: Anti-Climacus. Situado más arriba que Johannes Climacus, la máscara que figura firmando Migajas filosóficas y el Postscriptum, Anti-Climacus es el medio que moldea Kierkegaard para comunicar derechamente la exigencia cristiana, desde la perspectiva de una subjetividad que se reconoce en efecto como religiosa. Anti-Climacus sienta las bases para la conformación del espíritu subjetivo en La enfermedad mortal, puesta en vitrina el 30 de julio de 1849, y luego tensa la relación con lo externo en Ejercitación del cristianismo, aparecido el 25 de septiembre de 1850.

Sin alegar que sean los únicos, hay una tríada de temas que aparecen de manera recurrente en los manuscritos que Kierkegaard va acumulando en su mesa de trabajo: el individuo como categoría decisiva para la época, la multitud y las mayorías como los enemigos a combatir para frenar la deformación moderna, y el orden establecido como espacio por el que Kierkegaard lucha indirectamente a través de sus reclamaciones en contra de la desfachatez político-eclesiástica. En un bosquejo de 1847 que estaba contemplando como anexo de Mi punto de vista y que resuena con lo que después le compartiría a Kolderup-Rosenvinge, Kierkegaard asegura que en una época en la que "todo es política" ${ }^{57}$, lo que se necesita es la intervención religiosa. Esta resignificación de lo terrenal por medio de lo eterno, entraña para Kierkegaard la presencia del sujeto como instancia de conciencia y de reforzamiento interior: "El individuo singular es la categoría a través de la que, en un sentido religioso, debe pasar la época, la historia, la raza humana" 58 . En esta línea, Kierkegaard asume como objetivo central de su labor en tanto autor la recuperación de la singularidad y el quiebre con la ilusión moderna de que la fuerza está en el número. En Sobre mi actividad como escritor, Kierkegaard pone de lleno en la palestra que el movimiento

${ }^{57} \mathrm{PV}, 103$ / SKS 16, 83.

${ }^{58} \mathrm{PV}, 118$ / SKS 16, 98. 
de su producción es "llegar a lo simple" o, lo que es lo mismo, ir "desde el público hacia "el individuo singular" "59. Esta intención dirigida a la primitividad, que recuerda al impulso hacia el punto fijo de partida en la analogía ferroviaria que veíamos más arriba, cruza como espina dorsal las obras edificantes y homónimas de Kierkegaard, al tiempo que está implicada también en las piezas seudónimas estéticas, filosóficas y cristianas.

A esta clasificación final pertenece justamente Ejercitación del cristianismo. Complejizando el entramado creacional, Kierkegaard se añade como editor de este polémico libro de Anti-Climacus y se aventura además con un prefacio en el que advierte que el seudónimo fuerza el cristianismo desde el más alto grado de idealidad y que, dado que el requerimiento no puede ser diluido, lo que queda es hacer "un reconocimiento y una confesión acerca de uno mismo" $"$. Con esta pequeña garantía, Kierkegaard delinea Ejercitación del cristianismo como "un intento por encontrar, idealmente, una base para el orden establecido" ${ }^{1}$, esto es, como un contrapunto desde la demanda religiosa que azuce a la institucionalidad política a redefinir sus límites y aceptar su despliegue en lo que para la individualidad debería permanecer como relativo. Es cierto que lo capital es el individuo y su desarrollo de conciencia, pero arrimadas a este proceso vienen remodulaciones no sólo en la esfera interior, sino también en el ámbito exterior en el que se ve comprometido el sujeto. Si lo político alcanza este nivel de honestidad, Kierkegaard se muestra abierto a mantener un prioritarismo atento, una especie de neutralidad armada, que no implique ni la colisión ni el martirio de aquel que tiene en su espíritu la resolución de conciencia de lo eterno.

Las mismas tres aristas -individuo, multitud y orden establecido- se entrecruzan en los Papirer de este período. Alrededor de mayo de 1847, Kierkegaard presiente que "veremos que todo intento futuro de reforma, si es guiada por un verdadero reformador, estará dirigida contra la 'multitud', no contra el gobierno" ${ }^{2}$. En contraste con la seguridad mundano-histórica que proveía la monarquía, lo que asume Kierkegaard es que las revoluciones europeas tensarán un contexto en el que se deberá "empezar desde un punto diferente, a saber, el desarrollo intensivo interno del Estado" ${ }^{63}$, cuestión que

${ }^{59} \mathrm{PV}, 10$ / SKS 13, 17.

${ }^{60}$ Søren Kierkegaard, Ejercitación del cristianismo, trad. de Demetrio Gutiérrez, Madrid: Trotta, 2009, p. 29 / SKS 12, 15. Traducción modificada. Este prefacio se repite tres veces en Ejercitación del cristianismo, siempre al comienzo de cada serie.

${ }^{61}$ Ibíd., p. 18 / SKS 12, 25.

${ }^{62}$ JP 4, 4116 / SKS 20, 136, NB2:3.

${ }^{63}$ Ibíd. 
no remite a ningún otro registro que al del individuo singular. El ánimo de fortalecimiento de esta categoría a través de su producción, le permite machacar a Kierkegaard en sus papeles personales, en su obra publicada e incluso ante el mismo rey Cristián VIII, que su empresa ha sido "en servicio de lo establecido" ${ }^{64}$. No es que Kierkegaard esté fomentando algún tipo de remodulación externa, tal como le atribuiría Rudelbach más tarde, sino que está enfocado en que la institucionalidad, en tiempos en los que las masas decretan el poder, "necesita despertamiento y rehabilitación" "65. Así, Kierkegaard aprovecha este nicho que está cavando y se empieza a perfilar como el posible agente transformador: "[...] he presionado en la dirección de volverme un reformador [...]; si debo sucumbir, sucumbiré" ${ }^{66}$.

Durante los primeros meses de 1850, Kierkegaard traslada su indirecta labor política hacia su fuente existencial y desde ahí la vuelve a proyectar a lo externo. Marcando su sufrimiento como garantía de que su desempeño ha sido por la verdad, Kierkegaard desprecia la mundana cobardía de la multitud, que "ostenta el poder en el Estado" 67 , y de su medio de expresión: la prensa. En último término, lo que Kierkegaard lee como la principal corrupción en la afrenta abstracta de lo numérico, es que la imagen de la individualidad ha sido retocada por las mayorías y aquella resistencia que antes ejecutaba un individuo con todo en su contra se ha vuelto ahora motivo inmediato de admiración: "Aquellos que están a la cabeza de la multitud son por lejos la fuerza más potente y aun así disfrutan del honor y la estima que se les debe a los mártires" 68 .

Con esto desembocamos fácilmente hacia el Kierkegaard que veíamos a principios de 1851, en medio de su indignación con Rudelbach, reivindicando el asunto de conciencia del sujeto y una nueva interioridad que se conserva como tal, pero que implica la posibilidad siempre latente de la colisión e incluso del martirio ${ }^{69}$. Es este mismo Kierkegaard el que poco después pone frente a frente la exigencia existencial y la desastrosa confusión política:

No es la "doctrina" la que debe inspeccionarse críticamente y no es la "Iglesia" la que debe ser reformada, etc. etc.

No, son las existencias las que deben ser inspeccionadas críticamente. El

${ }^{64}$ JP 6, 6344 / SKS 21, 274, NB10:35.

65 Ibíd.

${ }^{66}$ Ibíd.

${ }^{67} \mathrm{JP}$ 3, 2950 / SKS 23, 29, NB15:40.

${ }^{68} \mathrm{JP}$ 4, 4174 / SKS 23, 44, NB15:65.

${ }^{69}$ Cfr. JP 2, 2130 / SKS 24, 218, NB23:26. 
hecho de que todo nuestro ámbito existencial sea ciertamente un sinsentido [al margen: y falta de carácter], implica que debemos hacerle una espantosa confesión al cristianismo.

Pero todos rechazamos este ámbito existencial y por eso mismo todos estos subterfugios y caprichos para decir que es la "doctrina" la que debe ser inspeccionada y que la Iglesia debe ser reformada, y el Estado, etc. $^{70}$

La muerte de J.P. Mynster, primado de la Iglesia protestante de Dinamarca y principal rostro de la alianza de los conservadores con los liberales, la instalación de H.L. Martensen como nuevo regente eclesiástico y la elección de P.G. Bang como primer ministro, fueron tres de los gatillantes externos que llevaron a Kierkegaard a perder la paciencia con el nuevo Estado danés y a cesar en su esperanza de reconocimientos ${ }^{71}$. El 18 de diciembre de 1854, Kierkegaard inicia un ataque y un boicot abierto al orden establecido y a la estructura de la Iglesia. Este conflicto, que asumió en soledad y como un asunto de conciencia, lo llevó a la muerte menos de un año después.

\section{Conclusión}

Más allá de su posterior distanciamiento, Herbert Marcuse inaugura en 1929 la recepción de Kierkegaard por parte de la Escuela de Frankfurt, apuntándolo como la encarnación del espíritu que promueve el desenvolvimiento concreto de la actividad filosófica. En "Ueber konkrete Philosophie", Marcuse ve con notorio entusiasmo que, en cada artículo, en cada folleto de su ataque final a la cristiandad en Dinamarca, Kierkegaard "concentra toda su lucha en la decisión en el instante histórico"72. A lo que apuesta subsecuentemente Kierkegaard con su publicidad, según Marcuse, es a un "movimiento concreto en el existente" "3 a que la filosofía haga de la "existencia humana contemporánea" 74 su directriz, a que la "existencia de cada singular"75 se ejecute más allá de una categoría abstracta de sujeto.

${ }^{70}$ JP 3, 3731 / SKS 24, 219, N23:30.

${ }^{71}$ Cfr. Bruce Kirmmse, "The Thunderstorm: Kierkegaard's Ecclesiology", Faith and Philosophy, vol. 17, no. 1, 2000, p. 96; Joakim Garff, Søren Kierkegaard. A Biography, trad. de Bruce Kirmmse, Princeton: Princeton University Press, 2005, p. 729.

${ }^{72}$ Herbert Marcuse, "Ueber konkrete Philosophie", Archiv für Sozialwissenschaft und Sozialpolitik, vol. 62, 1929, p. 124.

${ }^{73}$ Ibíd., p.124.

${ }^{74}$ Ibíd., p. 125.

${ }^{75}$ Ibíd., p. 126. 
En esta línea, Marcia Morgan, sintetizando el vínculo de Kierkegaard con la primera oleada de la teoría crítica y las dos por venir, señala que el énfasis de esta corriente "en los seres humanos individuales como locus del cambio social" 76 , tiene entre sus raíces precisamente en el posicionamiento de la singularidad que ejecuta Kierkegaard a partir de lo que podríamos llamar el vuelco político de su emprendimiento productivo religioso. Matizando el contexto de la difusión de Kierkegaard en Alemania y la fuerza de una cierta lectura tradicional, Morgan se da a la tarea de mostrar los vínculos entre la subjetividad kierkegaardiana y la propuesta crítica.

Martin Matuštík es uno de los que ha hecho esfuerzos más profundos por recuperar a Kierkegaard para el debate político contemporáneo y en especial para el que se sabe condicionado por las rupturas de sentido que cruzaron al mundo durante el siglo XX y que condicionaron el registro de pensamiento que llevaron adelante Horkheimer, Adorno, Lukács, el mismo Marcuse y posteriormente Habermas, entre otros. Modelando un Kierkegaard deliberativo y transgresor, Matuštík hace una asunción hermenéutica que es, desde mi punto de vista, muy responsable y provechosa:

Es verdad, la crítica de Kierkegaard deja intacto mucho del orden simbólico y material de su cultura y de su época. Pero no estamos de ningún modo obstaculizados para utilizar su descentrada y radicalmente honesta forma de volverse un escritor, un comunicador, un crítico y un activista, para revisar estas categorías en maneras que ni su correctivo perseguía ni su siglo permitía ${ }^{77}$.

Especificando esta estrategia de Matuštík, mi propuesta interpretativa general envuelve llevar a cabo un levantamiento histórico-filosófico, dirigido a las fuentes mismas, de lo que Kierkegaard fue desarrollando en diversos períodos y ante diversos fenómenos externos, para desaguar luego en esa apropiación a la que refiere Matuštík. Lo que intenté argumentar en este artículo pertenece al primer movimiento, dejando abierta la posibilidad de traducir las nociones del Kierkegaard enfrentado a la conmoción política en Europa y en Dinamarca, y resignificarlas como herramientas para analizar la figura del Estado y las consecuencias de un dominio irrestricto de ciertas mayorías de pertenencia.

${ }^{76}$ Marcia Morgan, Kierkegaard and Critical Theory, Lanham: Lexington Books, 2012, p. 1.

77 Martin Matuštík, "Kierkegaard as socio-political thinker and activist”, Man and World, vol. 27, 1994, p. 221. 
Estimo que existen visos de interpelación para nuestro tiempo en el modo en que Kierkegaard organiza sus propuestas en torno al individuo y el orden establecido, desdeñando la imposición de la multitud y de la homogeneidad cuantitativa, y tensando el involucramiento existencial del sujeto allí donde su conciencia esté implicada. Otra noción de comunidad puede emanar de esta renovada fuente.

\section{Bibliografía}

\section{Obras de Kierkegaard}

Kierkegaard, Søren, Christian Discourses, trad. de Howard y Edna Hong, Nueva Jersey: Princeton University Press, 1997.

_ Ejercitación del cristianismo, trad. de Demetrio Gutiérrez, Madrid: Trotta, 2009.

Kierkegaards Papirer, ed. P.A. Heiberg, V. Kuhr y E. Torsting, Copenhague: Gyndendalske Boghandel Forlag, 1909-1938.

_ La época presente, trad. de Manfred Svensson, Madrid: Trotta, 2012.

_L Las obras del amor, trad. de Demetrio Gutiérrez, Salamanca: Sígueme, 2006.

L Letters and Documents, trad. de Henrik Ronsenmeier, Nueva Jersey: Princeton University Press, 1978.

- Søren Kierkegaard's Journals and Papers, trad. de Howard y Edna Hong, vol. 1-6, Bloomington e Indiana: Indiana University Press, 1967-1978.

— Søren Kierkegaards Skrifter, ed. de Niels Jørgen Cappelørn, Joakim Garff, Johnny Kondrup, Alastair McKinnon y Fin Hauberg Mortensen, vol. 1-28, Copenhague: Gad Publishers, 1997-2013.

— The Corsair Affair, trad. de Howard y Edna Hong, Nueva Jersey: Princeton University Press, 1982.

— The Moment, trad. de Howard y Edna Hong, Nueva Jersey: Princeton University Press, 1998.

The Point of View, trad. de Howard y Edna Hong, Nueva Jersey: Princeton University Press, 1998.

Obras de otros autores

Garff, Joakim, Søren Kierkegaard. A Biography, trad. Bruce Kirmmse, Princeton: Princeton University Press, 2005. 
Kirmmse, Bruce, Kierkegaard in the Golden Age Denmark, Bloomington e Indianápolis: Indiana University Press, 1990.

"The Thunderstorm: Kierkegaard's Ecclesiology", Faith and Philosophy, vol. 17, no. 1, 2000.

Marcuse, Herbert, "Ueber konkrete Philosophie", Archiv für Sozialwissenschaft und Sozialpolitik, vol. 62, 1929.

Matuštík, Martin, "Kierkegaard as socio-political thinker and activist", Man and World, vol. 27, 1994.

Morgan, Marcia, Kierkegaard and Critical Theory, Lanham: Lexington Books, 2012

Tilley, Michael, "Herbert Marcuse: Social Critique, Haecker, and Kierkegaardian Individualism", en Kierkegaard's Influence on SocialPolitical Thought, ed. de Jon Stewart, Farnham: Ashgate, 2009. 